\title{
Preterm birth due to cervical insufficiency complicated by placenta accreta and postpartum haemorrhage managed by uterine artery embolisation
}

\author{
Elina Tetere $^{1 *}$, Anna Jekabsone ${ }^{1}$, Ieva Kalere ${ }^{1}$, Dace Matule ${ }^{2}$ \\ ${ }^{1}$ Department of Obstetrics \& Gynaecology, Riga Stradins University, Riga, Latvia \\ ${ }^{2}$ Department of Gynaecology, ARS Medical Company, Riga, Latvia
}

Received: 5 August 2014

Accepted: 19 August 2014

*Correspondence:

Dr. Elina Tetere,

E-mail: etetere@gmail.com

(C) 2014 Tetere E et al. This is an open-access article distributed under the terms of the Creative Commons Attribution Non-Commercial License, which permits unrestricted non-commercial use, distribution, and reproduction in any medium, provided the original work is properly cited.

\begin{abstract}
In this report, we present the case of a young woman undergoing her second pregnancy, with early detected shortened cervix resulting in cervical cerclage procedure. At gestational week 24/25, she presented at a hospital with signs of intra-amniotic infection and spontaneous rupture of membranes. This resulted in pathological preterm delivery with massive postpartum bleeding, which was managed by bilateral uterine artery embolization. Reasons for preterm birth and management options are discussed.
\end{abstract}

Keywords: Preterm birth, Cervical cerclage, Placenta accreta, Uterine artery embolization

\section{INTRODUCTION}

Preterm birth (PTB) is a severe pregnancy outcome, which is associated with high morbidity and mortality of the new-born; therefore, it is important to identify the risk factors involved. Although various causes of PTB, such as preeclampsia, intra-amniotic infection and foetal intrauterine growth restriction, are well recognized, the major factors of PTB remain idiopathic. Several risk factors have been investigated. One of the investigated risk factors for the development of cervical insufficiency is over-dilation of the cervix during curettage procedures. ${ }^{1}$ These procedures themselves are considered to be a risk factor for defective decidual formation and placenta accreta during the subsequent pregnancy. ${ }^{2}$ Both placenta accreta and intra-amniotic infection may lead to uterine atony and severe postpartum haemorrhage (PPH), which is the primary cause of nearly one-quarter of all maternal deaths globally. ${ }^{2,3}$ One of the possible ways to treat $\mathrm{PPH}$ is uterine artery embolization. This requires appropriate resources, and was done as a definitive method to manage PPH in this case.

\section{CASE REPORT}

A 27-year-old woman presented with her second pregnancy. In 2009, she had a vaginal term delivery which was complicated by PPH due to placental retention. In order to stop the haemorrhage, manual placental ablation and, later, two uterine reabrasions were performed due to placental tissue retention. In 2010, she had a uterine polyp, which was removed and a levonorgestrel-releasing intrauterine system was inserted (this was removed in 2012).

This pregnancy continued without complications until gestational week $11 / 12$, when progesterone therapy was started due to uterine hypertonus. A transvaginal ultrasound (TVUS) showed a cervical length of $41.5 \mathrm{~mm}$. On the next visit at week 15/16, the woman had mucous vaginal discharge and a cervical length of $27.1 \mathrm{~mm}$ was detected on the TVUS. At gestational week 18/19, the patient was admitted to a gynaecological hospital with complaints of tightening lower abdominal pain. A vaginal examination at admission revealed a dilated cervix and 
the amniotic sac was visualized. At this time, an emergency Cervical Cerclage (CC) was performed. One week after the procedure, the TVUS showed a cervical length of $18.6 \mathrm{~mm}$ (Figure 1). The patient was on progesterone, antibacterial and tocolytic therapy during her hospital stay. After being discharged, the patient continued fenoterol and progesterone therapy. At gestational week 24/25, the patient was admitted to a third level maternity care centre at 04:37 AM (local time), presenting with mucous bloody vaginal discharge, elevated blood pressure, axillary temperature of $37.5^{\circ} \mathrm{C}$ and signs of periodic uterine contractions. IV antibacterial therapy and glucocorticoids for respiratory distress syndrome prophylaxis were initiated. At 01:30 $\mathrm{PM}$, regular labour contractions began. At 02:00 PM, yellowish-green water with a smell broke. It was decided to continue the labour per vias naturales. At 07:15 PM, a spontaneous delivery resulted in the birth of a girl, weighing $660 \mathrm{~g}$ and $31 \mathrm{~cm}$ in length, Apgar score was 5 at the first minute and 6 at the fifth minute of life. The new-born was admitted to the Intensive Care Unit (ICU). At 07:30 PM, no signs of placental expulsion were detected and a PPH was observed. IV Oxytocin was administered. Manual and instrumental uterine cavity revision under IV anaesthesia was performed after noting that the placenta was strongly attached to the uterine wall, which gave rise to suspicions of an accrete placenta. A uterine cavity abrasion with removal of placental pieces was performed. Colporrhaphy was done due to a defect of the cervix. After failure to control the bleeding with the measures taken thus far, it was decided to perform a Bakri balloon tamponade. The bleeding ceased, but the patient's blood pressure at this time was $76 / 50 \mathrm{mmHg}$. The estimated total blood loss was $3 \mathrm{~L}$ and the patient was admitted to the ICU. At 10:00 PM, the patient complained of severe abdominal pain and the bleeding reoccurred. Bilateral Uterine Artery Embolization (UAE) was done by an invasive radiologist at 10:35 PM. The patient received antianaemic therapy including blood transfusions. Her hemodynamic state remained stable and her overall condition rapidly improved. She was discharged seven days later.

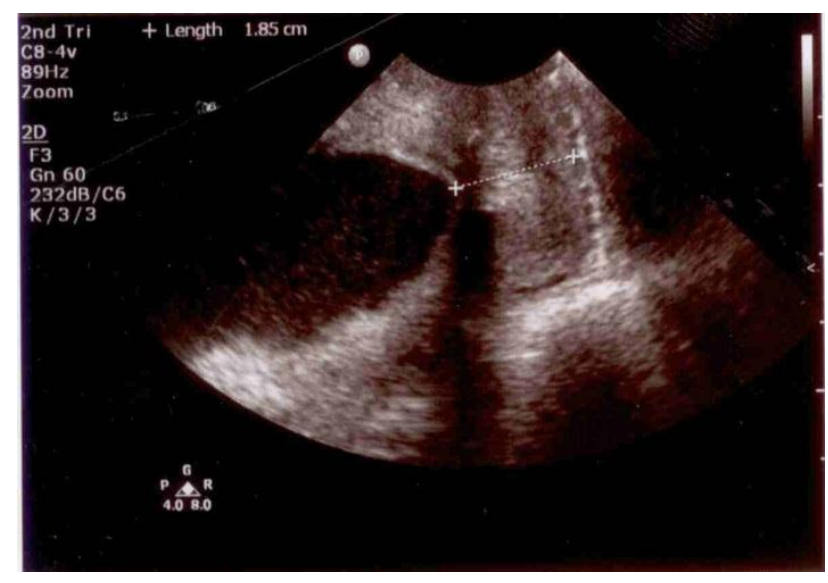

Figure 1: Shortened cervix on transvaginal ultrasonoscopy.

\section{DISCUSSION}

This case demonstrates a high-risk pregnancy with multiple risk factors: cervical insufficiency very early in pregnancy managed by $\mathrm{CC}$, infection, and placenta accreta, resulting in PTB. The role of each of these factors is unclear.

Shortened cervix is an independent risk factor for PTB. In this case, the shortened cervix was detected very early in pregnancy via an ultrasound, and a decision was made to use CC. The use of this method is controversial. As was presented in the Cochrane review, previous studies show that CC compared to conservative therapy has little or no effect in preventing early pregnancy loss and preterm delivery because $\mathrm{CC}$ is associated with a higher risk of infection. Only high risk pregnancies with short cervix seen on ultrasound could benefit from this procedure. ${ }^{4}$ It is known that infection can lead to placental inflammation, which is a risk factor for preterm delivery. ${ }^{5}$ However, a point which is also currently under discussion is whether a shortened cervix could have been an indicator of infection prior to cerclage. This would mean that the cervical insufficiency was only a symptom and $\mathrm{CC}$ was not the source of infection. It is hypothesized that a short cervix may be the only manifestation of intraamniotic infection. ${ }^{6}$

Placenta accreta is a pregnancy complication associated with a high risk of intrapartum and PPH. Due to lifethreatening blood loss, it is often managed by use of a hysterectomy, but now, uterine-sparing options are available. Although its aetiology is unknown, the most common risk factor for placenta accreta is the caesarean section. ${ }^{7}$ In this case, previous uterine cavity abrasions after the first delivery could have been the reason for structural changes in the uterus and the abnormal placentation observed.

The young age of the patient and further fertility were reasons to prefer a uterine-sparing strategy. Fertility rate and menstrual function following $\mathrm{UAE}$ is yet to be studied, but the first reports show no significant difference compared to the general population. ${ }^{8} \mathrm{UAE}$ is not widely used in Latvia, but, if available, it should be considered in young women with PPH.

\section{ACKNOWLEDGEMENTS}

We would like to express our profound gratitude to Dr. Sandra Vitina and all the other medical staff taking part in the care of this complicated case.

\section{Funding: No funding sources \\ Conflict of interest: None declared \\ Ethical approval: Not required}

\section{REFERENCES}

1. Vyas NA, Vink JS, Ghidini A, Pezzullo JC, Korker $\mathrm{V}$, Landy $\mathrm{HJ}$, et al. Risk factors for cervical 
insufficiency after term delivery. Am J Obstet Gynaecol. 2006;195(3):787-91.

2. Cunningham FG, Leveno KJ, Bloom SL, Hauth JC, Rouse DJ, Spong CY. Obstetrical haemorrhage. In: Cunningham FG, Leveno KJ, Bloom SL, Hauth JC, Rouse DJ, Spong CY, eds. Williams Obstetrics. 23rd ed. New York, NY: The McGraw-Hill; 2010: 777 795.

3. Tunçalp Ö, Souza JP, Gülmezoglu M. New WHO recommendations on prevention and treatment of postpartum hemorrhage. Int $\mathbf{J}$ Gynaecol Obstet. 2013;123(3):254-6.

4. Huy NVQ. Cervical stitch (cerclage) for preventing pregnancy loss in women: RHL commentary (last revised: 1 September 2007). The WHO Reproductive Health Library; Geneva: WHO; 2007.

5. McElrath TF, Hecht JL, Damman O, Boggess K, Onderdonk A, Markenson G, et al. Pregnancy disorders that lead to delivery before the 28th week of gestation: an epidemiologic approach to classification. Am J Epidemiol. 2008;168(9):980-9.

6. Hassan S, Romero R, Hendler I, Gomez R, Khalek $\mathrm{N}$, Espinoza $\mathrm{J}$, et al. A sonographic short cervix as the only clinical manifestation of intra-amniotic infection. J Perinat Med. 2006;34(1):13-9.

7. Garmi G, Salim R. Epidemiology, etiology, diagnosis, and management of placenta accrete. Obstet Gynaecol Int. 2012;2012:7.

8. Mohan PP, Hamblin MH, Vogelzang RL. Uterine artery embolization and its effect on fertility. J Vasc Intervent Radiol. 2013;7:925-30.

DOI: 10.5455/2320-1770.ijrcog20140975

Cite this article as: Tetere E, Jekabsone A, Kalere I, Matule D. Preterm birth due to cervical insufficiency complicated by placenta accreta and postpartum haemorrhage managed by uterine artery embolisation. Int J Reprod Contracept Obstet Gynecol 2014;3:746-8. 